Hydrol. Earth Syst. Sci., 15, 3071-3075, 2011

www.hydrol-earth-syst-sci.net/15/3071/2011/

doi:10.5194/hess-15-3071-2011

(C) Author(s) 2011. CC Attribution 3.0 License.

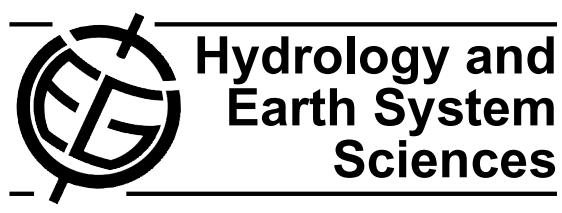

\title{
Technical note: Towards a continuous classification of climate using bivariate colour mapping
}

\author{
A. J. Teuling \\ Hydrology and Quantitative Water Management Group, Wageningen University, The Netherlands
}

Received: 29 April 2011 - Published in Hydrol. Earth Syst. Sci. Discuss.: 17 June 2011

Revised: 2 September 2011 - Accepted: 4 October 2011 - Published: 7 October 2011

\begin{abstract}
Climate is often defined in terms of discrete classes. Here I use bivariate colour mapping to show that the global distribution of Köppen-Geiger climate classes can largely be reproduced by combining the simple means of two key states of the climate system (i.e. air temperature and relative humidity). This allows for a classification that is not only continuous in space, but can be applied at and transferred between timescales ranging from days to decades.
\end{abstract}

\section{Introduction}

According to a popular phrase, we are told that "climate is what you expect, weather is what you get". Climate is thus defined as the weather averaged over a long period of time, usually $30 \mathrm{yr}$. Ideally, one would therefore rigorously define climate based on expected (i.e. mean) values of climate variables $X_{i}$ only:

Climate type $=f\left(E\left[X_{1}\right], E\left[X_{2}\right], \ldots\right)$.

Such a definition can be applied at any temporal (and spatial) scale ranging from minutes (provided $X_{i}$ is a continuous variable) to decades and could link short-term climate realizations and extremes to average conditions in that region or elsewhere. Here, I will explore the potential of such a classification.

Current classification systems are often scale-invariant and explicitly define their resolution in time and space (i.e. through a limited number of classes). The widely

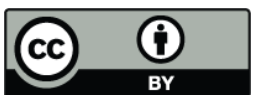

Correspondence to: A. J. Teuling

(ryan.teuling@wur.nl) used Köppen-Geiger system (Köppen, 1884, 1918), for instance, has a pre-defined number of classes and utilizes information on long-term averages on both yearly and monthly timescales. As a result, the Köppen-Geiger system accounts for effects of seasonality but variations on other timescales that are relevant to climate and ecosystem functioning are ignored (e.g. diurnal temperature range, decadal variations, El Niño). Discrete climate classes imply that changes in the distribution of climate zones can only be detected along climate class edges (for examples see Kim et al., 2008; Rubel and Kottek, 2010). In addition, the Köppen-Geiger system mixes statistics of a continuous atmospheric state (air temperature) and a discontinuous flux field with stochastic properties (precipitation). And while the Köppen-classification has been derived manually to predict vegetation patterns rather than climate itself, it does not make optimal use of the information contained in the meteorological observations (Cannon, 2011).

\section{Towards spatial continuity}

Considering these disadvantages, it is clear that the earth system and climate sciences community could benefit from a spatially continuous and conceptually more consistent classification of climate. It is also clear that any climate classification should at least contain measures of temperature $(T)$ and water availability. Rather than the amount of water that infiltrates into the soil or runs off during intermittent rain events (as in the Köppen classification) or that is stored in the soil (as in the Thornthwaite classification), I use screen-level relative humidity $(\mathrm{RH})$ as a robust and well-defined measure of water availability in the environment:

Climate type $=f(E[T], E[\mathrm{RH}])$.

Published by Copernicus Publications on behalf of the European Geosciences Union. 


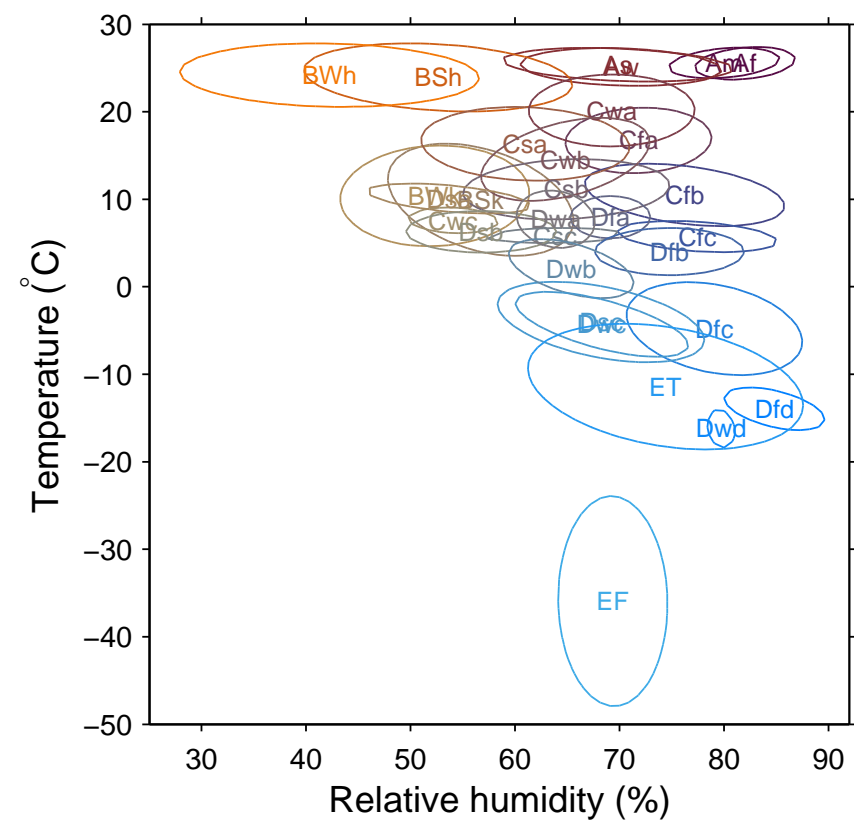

Fig. 1. Distribution of the Köppen-Geiger climate classes in the $T$, $\mathrm{RH}$-space. Contours are fitted bivariate Gaussian densities providing a measure of the spread within each class.

Note that both $T$ and $\mathrm{RH}$ are continuous variables defined for any time interval. For my analysis, I use gridded observations (10 min spatial resolution resampled to 0.5 degree resolution) for the period 1961-1990 compiled by the Climate Research Unit (e.g. New et al., 2002; Mitchell and Jones, 2005), and the Köppen-Geiger climate classification for the same period at 0.5 degree resolution as derived by Kottek et al. (2006).

Indeed, RH separates grid cells with classes that have similar average temperature but different rainfall characteristics, such as BWh, BSh, As/Aw and Am/Af (Fig. 1). Similarly, the different C, D, and E classes show a preference for a particular subspace. Note that the dependency of the Köppen classes on RH is indirect since the link between the amount of rain during discrete rain events used in the Köppen classification and the yearly average RH depends also on the reevaporation of rainwater into the atmosphere.

While conceptually straightforward, visualization of such classification requires both $T$ and RH to be plotted simultaneously. This can be achieved by a technique called bivariate colour mapping, in which every colour on the map corresponds not to a single value of a variable as in conventional colour mapping, but rather to a unique combination of two variables. Bivariate colour mapping can be an effective method to display how fields of two different variables co-vary in space. Examples of the application of bivariate colour maps to earth system sciences can be found in Albani et al. (2006), Teuling et al. (2009), and Miralles et al. (2011). For more information on bivariate colour mapping and construction of colour legends I refer to Teuling et al. (2011).
Figure 2a shows the current distribution of climate according to the Köppen-Geiger classification as derived by Kottek et al. (2006). The colour for each climate class is selected based on its mean position in the $T$, RH-space (Fig. 1). In this way, the global patterns can be directly compared to a map in which distribution of mean temperature and relative humidity have been plotted using bivariate colour mapping with a limited number of colours (Fig. 2b). The number of colours $(4 \times 4)$ has been chosen such that upon visual inspection the class boundaries roughly align with those in Fig. 2a. However, no optimization has been performed, the classes are equally-spaced in the $T$ - and $\mathrm{RH}$-space, and the resulting number of classes or colors (16) is different from the number in the Köppen-Geiger classification.

In spite of these limitations, the resulting maps are surprisingly similar, indicating that in addition to temperature, the yearly average rainfall as well as its seasonal distribution are reflected in the average relative humidity. Not only are the boundaries along wet-dry and warm-cold transitions well captured, even complex gradients, such as the combination of a north-south temperature gradient with a east-west humidity gradient in North-America, are captured. Differences occur over the Tibetan plateau, where the low humidity compared to regions with similar temperature is not reflected in the Köppen-Geiger map. Thus, by combining average temperature and relative humidity, the same global climate patterns emerge as those obtained by the much more complex Köppen-Geiger classification.

It should be noted, however, that these maps cannot readily be compared in a quantitative manner since this would require the difference between two colours (with 3 degrees of freedom) to be expressed in a single number. Also, the match between the two patterns depends on the (arbitrary) resolution in $\mathrm{RH}$ and $T$. An alternative quantitative comparison is provided in Table 1, where the number of overlapping cells between the Köppen-Geiger (Fig. 2a) and bivariate (Fig. 2b) classifications are listed. There is a good correspondence in patterns, in particular for the climate classes that span a wider range in temperature and humidity (bold values in Table 1) roughly corresponding to the $4 \times 4$ division in $\mathrm{RH}$ and $T$. To improve the correspondence with classes that span a smaller range in $\mathrm{RH}$ and $T$, a finer division in $\mathrm{RH}$ and $T$ would be needed; see also the evaluation of the Köppen-Geiger classes in the $T$, RH-space provided by Fig. 1.

An important advantage of the bivariate map (Fig. 2b) over the Köppen-Geiger classification (Fig. 2a), is that it can be directly transformed into a spatially continuous map (Fig. 3c) and can be calculated at any temporal resolution. This allows for mapping and evaluation of trends and small climate gradients that would otherwise fall within the boundaries of discrete climate classes, and also allows direct comparison of weather conditions at a daily timescale with climate averages. 
A Koppen-Geiger
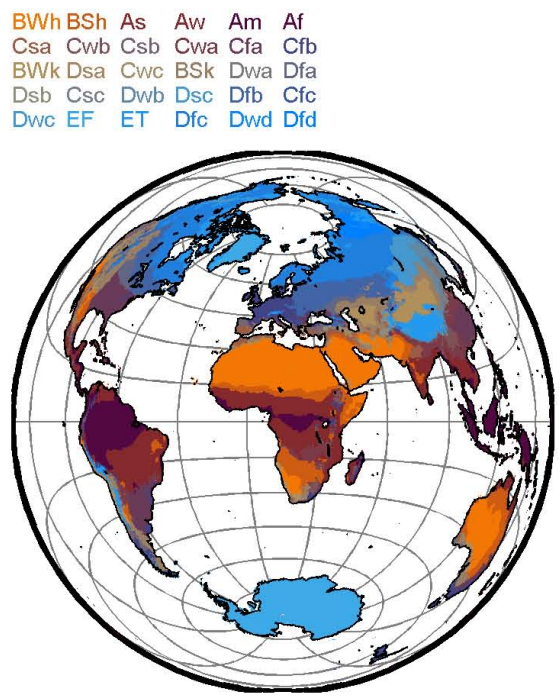

B Discrete bivariate

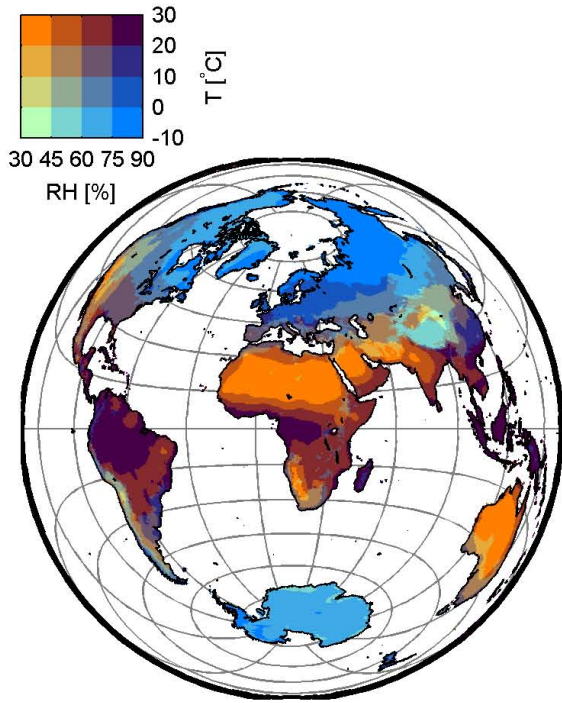

C Continuous bivariate

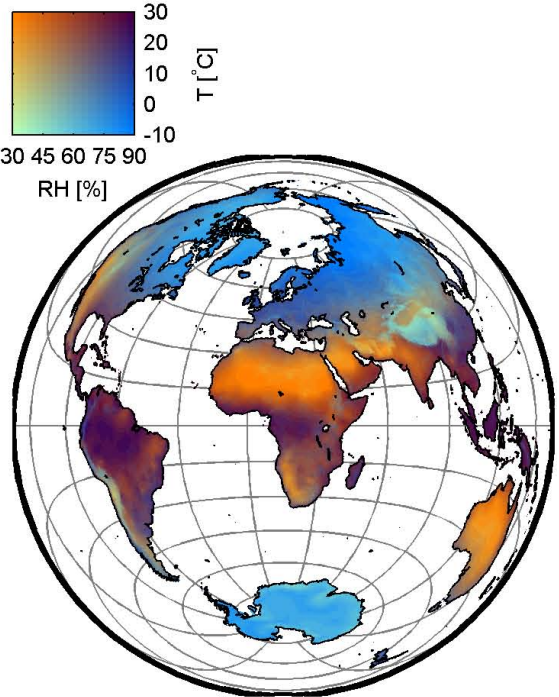

Fig. 2. Global distribution of climate zones. (A): Köppen-Geiger classification. Colouring is taken from Fig. 1. Data are taken from Kottek et al. (2006). (B): Discrete $(4 \times 4)$ bivariate classification of climate based on expected values of $T$ and RH. (C): (Near-)continuous (16 $\times 16)$ bivariate classification. Note the correspondence between (A) and (B). Data in (A) and (B) are gridded observations (10 min spatial resolution resampled to 0.5 degree resolution) for the period 1961-1990 compiled by the Climate Research Unit (e.g. New et al., 2002; Mitchell and Jones, 2005) extended with ERA-40 reanalysis over the Antarctic.
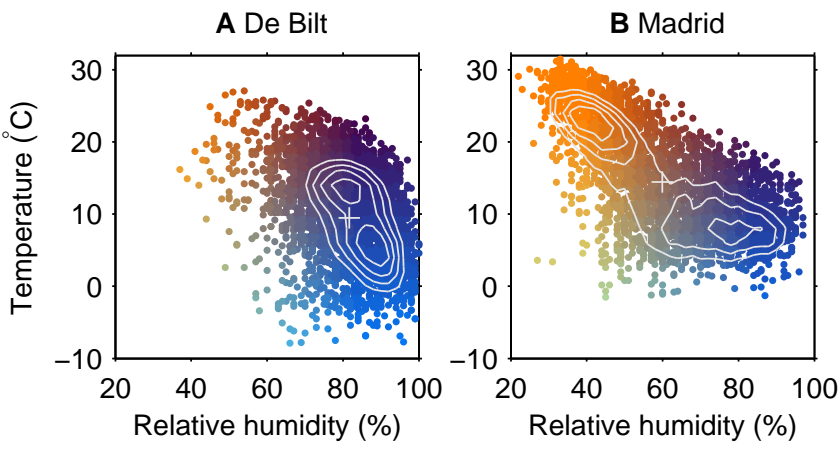

Fig. 3. Daily average temperature and relative humidity over the recent period 2001-2010 at De Bilt (A) and Madrid (B). Contour lines indicate the shape of the density maxima for the complete climate record. Crosses indicate mean values of RH and $T$. Observations are taken from the European Climate Assessment \& Dataset (ecad.knmi.nl).

\section{Linking weather and climate}

Next, I illustrate how colour can be used to visually link near-surface atmospheric conditions at different timescales. Figure 3 shows the distribution of long-term observations of daily average $T$ and RH at two European stations with different seasonal climate dynamics: De Bilt (The Netherlands, Cfb climate) and Madrid (Spain, Csa climate), for which data is available via the European Climate Assessment \& Dataset (ecad.knmi.nl). The individual days are plotted using the same colours as in Fig. 1. By doing so, the weather on one particular day (as characterized by the color that combines its $T$ and $\mathrm{RH}$ ) can be directly linked to average climate conditions in those regions in Fig. $2 \mathrm{c}$ that have the same colour. Alternatively, it could be linked to a bivariate colour map showing the expected values of $T$ and RH for that particular day.

It can be seen that on a daily timescale, weather conditions can vary over a range of $T$ and RH that cover the average conditions for most climate classes (see Fig. 1). During warm and dry summer conditions, air masses over The Netherlands often originate from the Sahara, and the orange colours indicate temperature and relative humidity typical for BWh climates. During cold extremes in winter, air masses typically have arctic origin and the light-blue colours indicate that these conditions correspond to average conditions for a Dfc climate. It should be noted that local processes can also have an important impact on temperature extremes in Europe, as was shown by Fischer et al. (2007) for warm extremes. Also note that seasonality induces preffered summer and winter states in the bivariate distribution of $T$ and $\mathrm{RH}$.

In the example of Madrid, the distribution differs in shape and orientation, and the preferred states are even more pronounced. Whereas winter conditions do not differ strongly from those in De Bilt, average summer conditions are typical for the BWh climate with summers being dry and warm. Thus, by looking at climate over multiple timescales, a more complete picture of local climate is obtained. 
Table 1. Correspondence between Fig. 2a and b expressed by the number of 0.5 degree cells overlapping each class in the Köppen-Geiger and bivariate classification. The last row and column represent the total sum for each classification class. Note that these numbers are not optimized values since the number of bivariate classes (16) and the temperature and relative humidity limits are chosen arbitrary. Bold values indicate which value is largest for each row and column simultaneously. Antarctica is omitted from the analysis.

\begin{tabular}{|c|c|c|c|c|c|c|c|c|c|c|c|c|c|c|c|c|c|}
\hline $\begin{array}{l}\mathrm{RH}[\%] \\
T\left[{ }^{\circ} \mathrm{C}\right]\end{array}$ & $\begin{array}{r}<45 \\
<0\end{array}$ & $\begin{array}{r}<45 \\
0-10\end{array}$ & $\begin{array}{r}<45 \\
10-20\end{array}$ & $\begin{array}{l}<45 \\
>20\end{array}$ & $\begin{array}{r}45-60 \\
<0\end{array}$ & $\begin{array}{r}45-60 \\
0-10\end{array}$ & $\begin{array}{l}45-60 \\
10-20\end{array}$ & $\begin{array}{r}45-60 \\
>20\end{array}$ & $\begin{array}{r}60-75 \\
<0\end{array}$ & $\begin{array}{r}60-75 \\
0-10\end{array}$ & $\begin{array}{l}60-75 \\
10-20\end{array}$ & $\begin{array}{r}60-75 \\
>20\end{array}$ & $\begin{array}{r}>75 \\
<0\end{array}$ & $\begin{array}{r}>75 \\
0-10\end{array}$ & $\begin{array}{r}>75 \\
10-20\end{array}$ & $\begin{array}{l}>75 \\
>20\end{array}$ & \\
\hline Af & 0 & 0 & 0 & 0 & 0 & 0 & 0 & 1 & 0 & 0 & 5 & 164 & 0 & 0 & 37 & 2407 & 2614 \\
\hline Am & 0 & 0 & 0 & 0 & 0 & 0 & 1 & 0 & 0 & 0 & 0 & 258 & 0 & 0 & 16 & 1594 & 1869 \\
\hline $\mathrm{Aw}$ & 0 & 0 & 0 & 4 & 0 & 0 & 10 & 860 & 0 & 0 & 21 & 3270 & 0 & 0 & 13 & 1907 & 6085 \\
\hline BSh & 0 & 0 & 73 & 862 & 0 & 0 & 322 & 915 & 0 & 0 & 104 & 796 & 0 & 0 & 5 & 69 & 3146 \\
\hline BSk & 4 & 21 & 203 & 0 & 75 & 692 & 1104 & 0 & 108 & 776 & 292 & 0 & 0 & 15 & 16 & 0 & 3306 \\
\hline BWk & 12 & 110 & 180 & 2 & 22 & 602 & 627 & 1 & 8 & 77 & 184 & 6 & 0 & 0 & 20 & 0 & 1851 \\
\hline Cfa & 0 & 0 & 4 & 0 & 0 & 1 & 136 & 44 & 0 & 18 & 1514 & 286 & 0 & 4 & 759 & 197 & 2963 \\
\hline $\mathrm{Cfb}$ & 0 & 0 & 0 & 0 & 0 & 44 & 99 & 3 & 0 & 221 & 441 & 7 & 0 & 1037 & 504 & 3 & 2359 \\
\hline $\mathrm{Cfc}$ & 0 & 0 & 0 & 0 & 0 & 1 & 3 & 0 & 0 & 63 & 0 & 0 & 0 & 130 & 0 & 0 & 197 \\
\hline Csa & 0 & 2 & 35 & 2 & 0 & 8 & 307 & 104 & 0 & 2 & 591 & 15 & 0 & 0 & 30 & 2 & 1098 \\
\hline Csb & 0 & 0 & 0 & 0 & 0 & 119 & 99 & 0 & 0 & 134 & 259 & 1 & 0 & 22 & 85 & 0 & 719 \\
\hline Csc & 0 & 0 & 0 & 0 & 0 & 2 & 0 & 0 & 0 & 9 & 0 & 0 & 0 & 0 & 0 & 0 & 11 \\
\hline Cwa & 0 & 0 & 0 & 0 & 0 & 0 & 41 & 82 & 0 & 1 & 369 & 601 & 0 & 0 & 114 & 299 & 1507 \\
\hline Cwb & 0 & 0 & 0 & 0 & 2 & 50 & 115 & 0 & 0 & 32 & 293 & 12 & 0 & 0 & 54 & 2 & 560 \\
\hline Cwc & 0 & 0 & 0 & 0 & 0 & 10 & 0 & 0 & 0 & 0 & 0 & 0 & 0 & 0 & 0 & 0 & 10 \\
\hline Dfa & 0 & 0 & 0 & 0 & 0 & 9 & 4 & 0 & 0 & 613 & 130 & 0 & 0 & 2 & 2 & 0 & 760 \\
\hline Dfb & 0 & 0 & 0 & 0 & 0 & 157 & 0 & 0 & 54 & 1950 & 2 & 0 & 70 & 2247 & 0 & 0 & 4480 \\
\hline Dfc & 0 & 0 & 0 & 0 & 47 & 68 & 0 & 0 & 2895 & 512 & 0 & 0 & 6251 & 1295 & 0 & 0 & 11068 \\
\hline Dfd & 0 & 0 & 0 & 0 & 0 & 0 & 0 & 0 & 0 & 0 & 0 & 0 & 1423 & 0 & 0 & 0 & 1423 \\
\hline Dsa & 0 & 2 & 6 & 0 & 0 & 26 & 32 & 0 & 0 & 9 & 4 & 0 & 0 & 0 & 0 & 0 & 79 \\
\hline Dsb & 0 & 6 & 0 & 0 & 1 & 133 & 2 & 0 & 0 & 63 & 2 & 0 & 0 & 0 & 0 & 0 & 207 \\
\hline Dsc & 0 & 0 & 0 & 0 & 19 & 30 & 0 & 0 & 168 & 16 & 0 & 0 & 22 & 7 & 0 & 0 & 262 \\
\hline Dwa & 0 & 0 & 0 & 0 & 0 & 21 & 9 & 0 & 0 & 222 & 71 & 0 & 0 & 0 & 0 & 0 & 323 \\
\hline Dwb & 0 & 0 & 0 & 0 & 2 & 129 & 0 & 0 & 181 & 330 & 2 & 0 & 7 & 0 & 0 & 0 & 651 \\
\hline Dwc & 1 & 0 & 0 & 0 & 73 & 88 & 0 & 0 & 949 & 29 & 0 & 0 & 175 & 0 & 0 & 0 & 1315 \\
\hline Dwd & 0 & 0 & 0 & 0 & 0 & 0 & 0 & 0 & 2 & 0 & 0 & 0 & 98 & 0 & 0 & 0 & 100 \\
\hline $\mathrm{EF}$ & 0 & 0 & 0 & 0 & 0 & 0 & 0 & 0 & 1175 & 0 & 0 & 0 & 815 & 0 & 0 & 0 & 1990 \\
\hline \multirow[t]{2}{*}{ ET } & 81 & 27 & 0 & 0 & 645 & 156 & 0 & 0 & 3240 & 106 & 1 & 0 & 3334 & 191 & 0 & 0 & 7781 \\
\hline & 98 & 168 & 959 & 5292 & 886 & 2346 & 3121 & 3404 & 8780 & 5183 & 4358 & 6314 & 12195 & 4950 & 1675 & 6625 & \\
\hline
\end{tabular}

\section{Conclusions}

In summary, by linking combinations of two spatially and temporally continuous fields (air temperature and relative humidity) to unique colours, a straightforward and easy-to-understand approximation of the distribution of global climate zones can be obtained. An important advantage of this method is that the continuous nature of the variables result in temporal means that are well-defined and meaningful at any time resolution. The proposed method can thus be used to bridge the gap between the weather that you get on any particular day, and the climate you expect at that location, or at any place on Earth.

Acknowledgements. I acknowledge financial support from The Netherlands Organisation for Scientific Research through Veni Grant 016.111.002.

Edited by: R. Woods and H. H. G. Savenije

\section{References}

Albani, M., Medvigy, D., Hurtt, G. C., and Moorcroft, P. R.: The contributions of land-use change, $\mathrm{CO}_{2}$ fertilization, and climate variability to the Eastern US carbon sink. Glob. Change Biol. 12, 2370-2390, 2006.

Cannon, A. J.: Köppen versus the computer: an objective comparison between the Köppen-Geiger climate classification and a multivariate regression tree, Hydrol. Earth Syst. Sci. Discuss., 8, 2345-2372, doi:10.5194/hessd-8-2345-2011, 2011.

Fischer, E. M., Seneviratne, S. I., Lüthi, D., and Schär, C.: Contribution of land-atmosphere coupling to recent European summer heat waves, Geophys. Res. Lett., 34, L06707, doi:10.1029/2006GL029068, 2007.

Kim, H. J., Wang, B., Ding, Q. H., and Chung, I. U.: Changes in arid climate over North China detected by the Koppen climate classification, J. Meteorol. Soc. Jpn., 86, 981-990, 2008.

Köppen, W.: Die Wärmezonen der Erde, nach der Dauer der heissen, gemässigten und kalten Zeit und nach der Wirkung der Wärme auf die organische Welt betrachtet (The thermal zones of the earth according to the duration of hot, moderate and cold periods and to the impact of heat on the organic world), Meteorol. Z. 1, 215-226, 1884 (translated and edited by Volken E. 
and Brönnimann, S., Meteorol. Z. 20, 351-360, 2011).

Köppen, W.: Klassifikation der Klimate nach Temperatur, Niederschlag und Jahresablauf (Classification of climates according to temperature, precipitation and seasonal cycle), Petermanns Geogr. Mitt. 64, 193-203, 243-248, 1918.

Kottek, M., Grieser, J., Beck, C., Rudolf, B., and Rubel, F.: World map of the Köppen-Geiger climate classification updated, Meteorol. Z., 15, 259-263, doi:10.1127/0941-2948/2006/0130, 2006.

Miralles, D. G., De Jeu, R. A. M., Gash, J. H., Holmes, T. R. H., and Dolman, A. J.: Magnitude and variability of land evaporation and its components at the global scale, Hydrol. Earth Syst. Sci., 15, 967-981, doi:10.5194/hess-15-967-2011, 2011.

Mitchell, T. D., and Jones, P. D.: An improved method of constructing a database of monthly climate observations and associated high-resolution grids, Int. J. Climatol., 25, 693-712, doi:10.1002/joc.1181, 2005.
New, M., Lister, D., Hulme, M., and Makin, I.: A high resolution data set of surface climate over global land areas, Clim. Res., 21, 1-25, 2002.

Rubel, F. and Kottek, M.: Observed and projected climate shifts 1901-2100 depicted by world maps of the KöppenGeiger climate classification, Meteorol. Z., 19, 135-141, doi:10.1127/0941-2948/2010/0430, 2010.

Teuling, A. J., Hirschi, M., Ohmura, A., Wild, M., Reichstein, M., Ciais, P., Buchmann, N., Ammann, C., Montagnani, L., Richardson, A. D., Wohlfahrt, G., and Seneviratne, S. I.: A regional perspective on trends in continental evaporation, Geophys. Res. Lett., 36, L02404, doi:10.1029/2008GL036584, 2009.

Teuling, A. J., Stöckli, R., and Seneviratne, S. I.: Bivariate colour maps for visualizing climate data, Int. J. Climatol., 31, 14081412, doi:10.1002/joc.2153, 2011. 